Check for updates

Cite this: Mater. Adv., 2020, 1,2418

Received 12th July 2020

Accepted 6th September 2020

DOI: 10.1039/d0ma00501k

rsc.li/materials-advances

\title{
BCN monolayer for high capacity Al-based dual-ion batteries $\dagger$
}

\author{
Hariom Saini, (D) Sandeep Das (D) and Biswarup Pathak (D)*
}

\begin{abstract}
Recent advances in the field of Al dual-ion batteries have put forward a major challenge of developing a novel and advanced cathode material that can provide high specific capacity, besides maintaining a constant high voltage. In this context, significant research has been carried out to identify new electrochemical energy storage materials, which suggest the applicability of low dimensional materials as an excellent choice due to their high surface-to-volume ratio. Herein, we perform first principles calculations to investigate the $\mathrm{BCN}$ monolayer as a suitable cathode material for Al dual-ion batteries. $\mathrm{AlCl}_{4}$ has been found to reversibly adsorb on the BCN monolayer with a significant charge transfer of $0.9|e|$ from $\mathrm{BCN}$ to $\mathrm{AlCl}_{4}$, indicating the oxidation of $\mathrm{BCN}$ monolayer during the charging process. Moreover, the BCN monolayer shows excellent structural stability on systematically increasing the concentration of adsorbed $\mathrm{AlCl}_{4}$, and could provide an open circuit voltage of $1.8 \mathrm{~V}$ (average voltage is $1.43 \mathrm{~V}$ ) with a high specific capacity of $316.9 \mathrm{~mA} \mathrm{~h}_{\mathrm{BCN}}{ }^{-1}$ at the maximum concentration of $\mathrm{AlCl}_{4}$ adsorption. The adsorption of $\mathrm{AlCl}_{4}$ also enables good electronic conductivity. Diffusion energy calculations reveal a minimum energy barrier of $0.12 \mathrm{eV}$ for the migration of $\mathrm{AlCl}_{4}$ within $\mathrm{BCN}$, ensuring a fast charge/discharge rate. Consequently, these findings suggest that the BCN monolayer could be a potential cathode material for Al dual-ion batteries, and motivates us to carry out further studies on similar low dimensional materials to improve the performance of Al dual-ion batteries.
\end{abstract}

\section{Introduction}

With the continuously increasing energy demand, secondary batteries have been widely used as energy conversion and storage units in devices, ranging from portable electronics to heavy electronic vehicles. ${ }^{1,2}$ Li-ion batteries and lead-acid batteries, being the most commercialized batteries, are quite efficient but have certain limitations in terms of safety, abundance and manufacturing cost. ${ }^{3-7}$ In this context, multivalent metal ion ( $\mathrm{Mg}, \mathrm{Zn}, \mathrm{Al}$ ) batteries can be a better choice due to their high abundance, low cost and high volumetric capacity. $^{8-15}$ Amongst the recently developed batteries, Al batteries have garnered interest due to the higher abundance (third most abundant metal in earth's crust), high gravimetric

Discipline of Chemistry, Indian Institute of Technology (IIT) Indore, Simrol, Indore 453552, India. E-mail: biswarup@iiti.ac.in

$\dagger$ Electronic supplementary information (ESI) available: The total energy vs. time plot for AIMD simulation with optimized final structures, optimized structures of $\mathrm{AlCl}_{4}$ adsorption at all possible adsorption sites of the BCN monolayer, relative adsorption energy for all possible adsorption sites available for the adsorption of $\mathrm{AlCl}_{4}$ and the average distance of adsorbed $\mathrm{AlCl}_{4}$ from the BCN monolayer, side and top views of the most stable configuration of the $\mathrm{AlCl}_{4}$-adsorbed $\mathrm{BCN}$ monolayer at different concentrations, optimized configuration of $15 \mathrm{AlCl}_{4}$ adsorbed system, DOS plots for 7, 10, $14 \mathrm{AlCl}_{4}$ adsorbed systems, and the optimized highest energy transition states for different possible pathways of $\mathrm{AlCl}_{4}$ diffusion. See DOI: 10.1039/d0ma00501k
( $\left.3 \mathrm{~A} \mathrm{~h} \mathrm{~g}^{-1}\right)$ and volumetric capacity (8.04 $\mathrm{A} \mathrm{h} \mathrm{cm}^{-3}$ ) compared to other metal ions. ${ }^{12-15}$ However, these merits are due to the anodic part and there is an essential need to look out for materials to improve the cathodic part, which can provide suitable electrochemical properties. Lin et al. assembled an $\mathrm{Al}$ battery having Al metal as an anode and three dimensional graphitic foam as a cathode in an ionic liquid electrolyte of $[\mathrm{EMIm}] \mathrm{Cl} / \mathrm{AlCl}_{3}$ (molar ratio $1: 1.3$ ) whose working mechanism involves the reversible intercalation/deintercalation of $\mathrm{AlCl}_{4}$ on the cathode side during the charging/discharging process. ${ }^{16,17}$ Simultaneously, the electrochemical deposition/dissolution of $\mathrm{Al}$ takes place at the anodic part during charging/discharging. This cell provides a good discharge voltage of $2 \mathrm{~V}$ with a specific capacity of $70 \mathrm{~mA} \mathrm{~h}^{-1}$ and an ultrahigh charge-discharge rate. Since then, different forms of graphite and conducting polymers have been utilized as cathode materials for $\mathrm{Al}$ batteries. ${ }^{13,18-22}$ Similarly, theoretical studies have also been carried out for carbonaceous cathode materials, such as $\mathrm{BC}_{3}$, $\mathrm{C}_{3} \mathrm{~N}$ and $\mathrm{G} / \mathrm{h}-\mathrm{BN} .^{23-25}$ Among various investigated cathode materials, low dimensional materials have shown improved results in terms of storage capacity, voltage, and cyclic stability. ${ }^{22,26-29}$ Importantly, two-dimensional materials have attracted special interest due to their high surface-volume ratio, mechanical flexibility, cycle life and thermal stability. ${ }^{30-33}$ Thus, for the improvement of the electrochemical properties 
of $\mathrm{Al}$ dual-ion batteries, there is a need to look out for other lowdimensional cathode materials. One such potential candidate is the $2 \mathrm{D}$ hexagonal graphenic $\mathrm{BCN}$ monolayer, recently synthesized by Beniwal and co-workers using bis-BN cyclohexane $\left(\mathrm{B}_{2} \mathrm{C}_{2} \mathrm{~N}_{2} \mathrm{H}_{12}\right)$ as a precursor for the epitaxial growth of the BCN monolayer on an $\operatorname{Ir}(111)$ substrate under ultrahigh vacuum. ${ }^{34}$ Graphene and hBN were also previously synthesized on $\operatorname{Ir}(111)$ and $\operatorname{Rh}(111)$ substrates. ${ }^{35-37}$ The authors further predict that due to strong intermolecular bonding between the atoms in the monolayer, free-standing monolayers can be obtained by exfoliation. ${ }^{34}$ In previous studies, we have observed that $\mathrm{BC}_{3}$ gives lower capacity with higher voltage for bulk systems, while $\mathrm{C}_{3} \mathrm{~N}$ delivers higher capacity with lower voltage compared to graphite. ${ }^{23,24} \mathrm{BCN}$ is isoelectronic in nature to graphene, but has both electron-deficient $\mathrm{B}$ and electron-rich $\mathrm{N}$ atoms, which may provide a unique adsorption environment for $\mathrm{AlCl}_{4}$. BCN is semiconducting in nature with a bandgap $(1.50 \mathrm{eV})$ that is intermediate between graphene and h-BN. ${ }^{34}$ Apart from these features, BCN shows higher directional anisotropy than graphene, suggesting a lower barrier for ion diffusion. ${ }^{38}$ Moreover, BCN has a smaller Young's modulus value and higher flexibility than graphene, which justifies its mechanical stability. ${ }^{38}$ All of these properties suggest that the $\mathrm{BCN}$ monolayer may be a potential electrode material candidate.

In this work, we have theoretically investigated the electrochemical properties of $\mathrm{BCN}$ as a cathode material for Al dualion batteries using density functional theory (DFT). We have considered a configuration of the $\mathrm{BCN}$ monolayer containing equal proportions of $\mathrm{B}, \mathrm{C}$ and $\mathrm{N}$ atoms, and studied the adsorption behavior and nature of interaction of $\mathrm{AlCl}_{4}$ on the BCN monolayer. The electronic properties have been determined through density of states (DOS) calculation of pristine $\mathrm{BCN}$ and $\mathrm{AlCl}_{4}$-adsorbed $\mathrm{BCN}$. The electrochemical properties have been examined by subjecting the monolayer to step-bystep $\mathrm{AlCl}_{4}$ adsorption. The diffusion characteristics were also carried out and overall, our results point towards the aptness of the BCN monolayer as an $\mathrm{Al}$ dual-ion battery cathode.

\section{Computational details}

The first principles calculations were carried out using the projector-augmented wave (PAW) method, as implemented in the Vienna $\mathrm{Ab}$ Initio Simulation Package (VASP). ${ }^{39-42}$ The generalized gradient approximation of Perdew-Burke-Ernzerhof (GGA-PBE) was used for describing the exchange-correlation potential, along with a plane-wave cut-off energy of $470 \mathrm{eV} .{ }^{43}$ All structures were fully optimized until the total energy convergence criteria of $10^{-5} \mathrm{eV}$ were met, and the HellmannFeynman forces on all atoms were less than $0.01 \mathrm{eV} \AA^{-1}$. A $\Gamma$-centered $k$-point grid of $9 \times 17 \times 1$ was used for the unit cell optimization, while a $5 \times 5 \times 1 \Gamma$-centered $k$-point grid was used for the $2 \times 4 \times 1$ supercell optimization. To avoid all periodic interactions, a vacuum of $20 \AA$ was considered along the $z$-direction. The DFT-D3 approach was used to include van der Waals interactions and dispersion energy corrections. ${ }^{44}$ To calculate the diffusion energy barrier for the $\mathrm{AlCl}_{4}$ molecule across the $\mathrm{BCN}$ monolayer, the climbing image nudged elastic band (CI-NEB) method was used by considering six intermediate images between the fully optimized initial and final structural geometry with the energy convergence criteria of $10^{-4} \mathrm{eV}$ for each image. ${ }^{45}$ Bader charge analysis was performed by means of the Henkelman program, using the near grid algorithm refine edge method to understand the extent of charge transfer from BCN to $\mathrm{AlCl}_{4} \cdot{ }^{46-49}$ DOS calculations were performed using a $\Gamma$-centered $k$-point grid of $15 \times 15 \times 3$ for the $\mathrm{BCN}$ monolayer and $\mathrm{AlCl}_{4}$-adsorbed BCN monolayer. To examine the thermal stability of the $2 \times 4 \times 1$ BCN monolayer, we performed ab initio molecular dynamics (AIMD) simulations using the Nosé thermostat model. ${ }^{50}$ A $k$-point grid of $5 \times 5 \times 1$ was considered to perform the simulation at 300 and $400 \mathrm{~K}$, as the batteries were expected to work using room temperature ionic liquid electrolyte for 10 picoseconds (ps) with a time step of 1 femtosecond ( $\mathrm{fs}$ ).

The overall cell reaction for the adsorption of $x$ number of $\mathrm{AlCl}_{4}$ molecules on the BCN monolayer can be written as:

$$
\begin{gathered}
\frac{3}{x}\left[\left(\mathrm{AlCl}_{4}\right)_{x} \mathrm{BCN}\right]+4\left[\mathrm{EMI}^{+} \mathrm{AlCl}_{4}^{-}\right]+\mathrm{Al} \\
\leftrightarrow \frac{3}{x}[\mathrm{BCN}]+4\left[\mathrm{EMI}^{+} \mathrm{Al}_{2} \mathrm{Cl}_{7}^{-}\right]
\end{gathered}
$$

The cell voltage can be calculated by the Nernst equation,

$$
V=-\frac{\Delta G_{\text {cell }}}{z F}
$$

where $\Delta G_{\text {cell }}$ is the change in Gibbs free energy of the cell reaction, $z$ is the total number of electrons involved in the cell reaction, and $F$ stands for the Faraday constant. $\Delta G$ for a reaction is given as

$$
\Delta G_{\text {cell }}=\Delta E_{\text {cell }}+P \Delta V_{\text {cell }}-T \Delta S_{\text {cell }}
$$

At $0 \mathrm{~K}$ temperature, the contribution of the volume effect $\left(V_{\text {cell }}\right)$ and entropy $\left(S_{\text {cell }}\right)$ can be neglected. Hence, $\Delta G_{\text {cell }}$ can be approximated to the change in internal energy $\left(\Delta E_{\text {cell }}\right){ }^{51}$ This change in the internal energy for the overall cell can be calculated by eqn (4).

$$
\begin{aligned}
\Delta E_{\mathrm{cell}}= & \left\{\frac{3}{x} E_{\mathrm{BCN}}+4 E_{\left[\mathrm{EMI}^{+} \mathrm{Al}_{2} \mathrm{Cl}_{7^{-}}\right]}\right\} \\
& -\left\{\frac{3}{x} E_{\left[\left(\mathrm{AlCl}_{4}\right)_{x} \mathrm{BCN}\right]}+4 E_{\left[\mathrm{EMI}^{+} \mathrm{AlCl}_{4}^{-}\right]}+E_{\mathrm{Al}}\right\}
\end{aligned}
$$

where $E_{\mathrm{BCN}}$ is the total energy of the BCN system, while $E_{\left[(\mathrm{AlCl} 4)_{x} \mathrm{BCN}\right]}, E_{\left[\mathrm{EMI}^{+} \mathrm{Al}_{2} \mathrm{Cl}_{7}{ }^{-}\right]}$, and $E_{\left[\mathrm{EMI}^{+} \mathrm{AlCl}_{4}{ }^{-}\right]}$are the total energies of the $\mathrm{AlCl}_{4}$-absorbed $\mathrm{BCN}$ system, $\mathrm{EMI}^{+} \mathrm{Al}_{2} \mathrm{Cl}_{7}{ }^{-}$and $\mathrm{EMI}^{+}$ $\mathrm{AlCl}_{4}{ }^{-}$, respectively. $E_{\mathrm{Al}}$ is the energy per $\mathrm{Al}$ atom in its bulk. $E_{\left[\mathrm{EMI}^{+} \mathrm{Al}_{2} \mathrm{Cl}_{7}^{-}\right]}$and $E_{\left[\mathrm{EMI}^{+} \mathrm{Al}_{2} \mathrm{Cl}_{7}^{-}\right]}$were calculated by optimizing $\mathrm{EMI}^{+} \mathrm{Al}_{2} \mathrm{Cl}_{7}{ }^{-}$and $\mathrm{EMI}^{+} \mathrm{AlCl}_{4}{ }^{-}$as ion pairs in a box due to the unavailability of their crystal structures. The solvent effect was not considered in our calculation, as it has been reported that the difference between the solvation energies of $\mathrm{AlCl}_{4}{ }^{-}$and $\mathrm{Al}_{2} \mathrm{Cl}_{7}{ }^{-}$is very small $(\sim 0.1 \mathrm{eV})$ in such cases. ${ }^{52}$

Therefore, the voltage $(V)$ for the system can be calculated by using eqn (5), 


$$
V=\frac{\left(\left\{\frac{3}{x} E_{\left[\left(\mathrm{AlCl}_{4}\right)_{x} \mathrm{BCN}\right]}+4 E_{\left[\mathrm{EMI}^{+} \mathrm{AlCl}_{4}^{-}\right]}+E_{\mathrm{Al}}\right\}-\left\{\frac{3}{x} E_{\mathrm{BCN}}+4 E_{\left[\mathrm{EMI}^{+} \mathrm{Al}_{2} \mathrm{Cl}_{7}^{-}\right]}\right\}\right)}{z F}
$$

where $z$ is the electronic charge. However, the specific capacity $(C)$ can be calculated by using eqn (6),

$$
C=\frac{z x F}{M_{\mathrm{f}}}
$$

where $z$ is the number of electrons transferred per formula unit, $x$ is the number of $\mathrm{AlCl}_{4}{ }^{-}$adsorbed on the BCN monolayer, $F$ is the Faraday constant and $M_{\mathrm{f}}$ is the mass of the BCN formula unit.

\section{Results and discussion}

\subsection{Structural stability of $\mathrm{BCN}$}

Fig. 1a-c show the three most commonly studied configurations of BCN, which contain $\mathrm{B}, \mathrm{C}$ and $\mathrm{N}$ atoms in the same stoichiometric ratio of $1: 1: 1$, with the arrangement of atoms and the connectivity between them being different. They are made up of different hexagonal units, as configuration (a) consists of a $\mathrm{B}_{2} \mathrm{C}_{2} \mathrm{~N}_{2}$ unit, while (b) is composed of $\mathrm{B}_{2} \mathrm{C}_{2} \mathrm{~N}_{2}, \mathrm{~B}_{2} \mathrm{C}_{3} \mathrm{~N}, \mathrm{BC}_{3} \mathrm{~N}_{2}$, and $\mathrm{B}_{3} \mathrm{~N}_{3}$ units, and (c) is made up of $\mathrm{B}_{2} \mathrm{C}_{2} \mathrm{~N}_{2}, \mathrm{~B}_{3} \mathrm{~N}_{3}, \mathrm{~B}_{3} \mathrm{C}_{3}$, and $\mathrm{C}_{3} \mathrm{~N}_{3}$ units. Among all three configurations, (a) was found to be relatively most stable energetically, followed by (b) and (c). The monolayer configurations (a) and (b) have $\mathrm{B}-\mathrm{C}, \mathrm{B}-\mathrm{N}, \mathrm{C}-\mathrm{N}$ and $\mathrm{C}-\mathrm{C}$ connecting bonds, while (c) does not have any $\mathrm{C}-\mathrm{C}$ bonds. Upon comparing the bond lengths, we found that the $\mathrm{C}-\mathrm{C}$ bonds were shortest with a bond length of $1.38 \AA$, followed by $\mathrm{C}-\mathrm{N}, \mathrm{B}-\mathrm{N}$ and $\mathrm{B}-\mathrm{C}$ with bond lengths of $1.40 \AA$ A $1.45 \AA$, and $1.54 \AA$, respectively. This explains the lower stability of monolayer (c) with respect to (a) and (b), as it does not have strong $\mathrm{C}-\mathrm{C}$ bonds. In contrast, monolayer (a) has the maximum number of $\mathrm{C}-\mathrm{C}$ bonds, and is thus found to be the most stable. This is consistent with a previous theoretical study stating that the most stable $\mathrm{BCN}$ structures tend to maximize the number of $\mathrm{B}-\mathrm{N}$ and $\mathrm{C}-\mathrm{C}$ bonds. ${ }^{35}$ The higher stability of configuration (a) was also previously reported on the basis of the computed electronic energy and relative cohesive energy. ${ }^{34,38}$ Our cohesive energy calculations yielded a value of $-8.38 \mathrm{eV}$ per atom for the $\mathrm{BCN}$ unit cell of configuration (a), which is comparable to our calculated value of graphene $(-8.9 \mathrm{eV})$. The reported value for graphene is around $-8.1 \mathrm{eV} .^{53}$ Thus, the monolayer once formed will not spontaneously decompose into individual atoms.

Henceforth, we have adopted configuration (a) of the BCN monolayer to construct a $2 \times 4 \times 1$ supercell, as presented in Fig. 1d for investigating the suitability of BCN as a cathode material. To start with, we have examined the thermal stability of the $2 \times 4 \times 1$ monolayer. The effect of temperature on the phase stability was analyzed at 300 and $400 \mathrm{~K}$. There is no appreciable energy change throughout the simulation for both cases, as shown in Fig. S1a and b (ESI $\dagger$ ). Furthermore, we present the snapshots of the final structure after simulation in Fig. S1d and e (ESI $\dagger)$, which do not show much deviation from the initial structure. The graphene-like lattice structure is also retained at the end of simulation. Hence, we can consider our BCN monolayer supercell to be thermally stable.

\subsection{Adsorption properties of $\mathrm{AlCl}_{4}$}

During the charging of the $\mathrm{Al}$ dual-ion battery, the $\mathrm{AlCl}_{4}$ intercalates/adsorbs into the cathode material. Hence, in order to study the adsorption properties of $\mathrm{AlCl}_{4}$, both planar and tetrahedral configurations of $\mathrm{AlCl}_{4}$ have been considered for adsorption on the $\mathrm{BCN}$ monolayer. However, $\mathrm{AlCl}_{4}$ prefers the tetrahedral geometry after the adsorption on the $\mathrm{BCN}$ monolayer, as reported earlier for other carbonaceous cathodes. $^{17,23-25}$ To identify the most stable site, all available possibilities were considered, as shown in Fig. 1d for a $2 \times$ $4 \times 1$ supercell. Nine stable adsorption sites could be identified, which comprise the three top sites (B top, $\mathrm{C}$ top and $\mathrm{N}$ top), four bridge sites ( $\mathrm{B}-\mathrm{C}$ bridge, $\mathrm{B}-\mathrm{N}$ bridge, $\mathrm{C}-\mathrm{N}$ bridge and $\mathrm{C}-\mathrm{C}$ bridge $)$ and two hollow sites $(\mathrm{C}-\mathrm{B}-\mathrm{N}-\mathrm{C}-\mathrm{B}-\mathrm{N}$ and $\mathrm{C}-\mathrm{C}-$ $\mathrm{B}-\mathrm{N}-\mathrm{B}-\mathrm{N}$ rings). The optimized structures of $\mathrm{AlCl}_{4}$ adsorption at these sites are also represented in Fig. $\mathrm{S} 2$ (ESI $\dagger$ ). The relative adsorption energies of these sites are given in Table S1 (ESI $\dagger$ ). The adsorption energies ( $\left.E_{\text {adsorption}}\right)$ corresponding to these sites have been calculated by using eqn (7).

$$
E_{\text {adsorption }}=\left(E_{\mathrm{BCN}+\mathrm{AlCl}_{4}}-E_{\mathrm{BCN}}-\mathrm{E}_{\mathrm{AlCl}_{4}}\right)
$$

where $E_{\mathrm{BCN}+\mathrm{AlCl}_{4}}$ and $E_{\mathrm{BCN}}$ are the total energies of the $\mathrm{BCN}$ system with and without $\mathrm{AlCl}_{4}$, respectively, while $\mathrm{E}_{\mathrm{AlCl}_{4}}$ is the total energy of one $\mathrm{AlCl}_{4}$ molecule. Hence, a more negative value of adsorption energy signifies the more stable adsorption of $\mathrm{AlCl}_{4}$ on that site. As a result, the $\mathrm{AlCl}_{4}$ adsorption is found to be most stable $(-2.36 \mathrm{eV})$ at Site 8 , which corresponds to the hollow site surrounded by the $\mathrm{C}-\mathrm{C}-\mathrm{B}-\mathrm{N}-\mathrm{B}-\mathrm{N}$ ring, as illustrated in Fig. 1d. The average distance of $\mathrm{Al}$ of $\mathrm{AlCl}_{4}$ from $\mathrm{BCN}$ monolayer on its adsorption at the hollow site surrounded by $\mathrm{C}-\mathrm{C}-\mathrm{B}-\mathrm{N}-\mathrm{B}-\mathrm{N}$ ring is also least (3.85 $\mathrm{A}$ ) among all the sites, as represented in Table $\mathrm{S} 1$ (ESI $\dagger$ ). The distance between $\mathrm{AlCl}_{4}$ and the monolayer can be justified by the absence of any overlap between the electron clouds of the monolayer and $\mathrm{AlCl}_{4}$ anion, as the interaction can be thought of as predominantly anion- $\pi$ type. This has been the case in the previously reported adsorption of $\mathrm{AlCl}_{4}$ in few-layered graphene, where the distance between $\mathrm{C}$ and $\mathrm{Cl}$ was also found to be more than $3 \AA$, as the $\mathrm{Cl}$ atoms have an ionic radii of $1.67 \AA$ and the overall size of $\mathrm{AlCl}_{4}$ is estimated to be $6.09 \AA^{54}{ }^{54}$ The adsorption of $\mathrm{AlCl}_{4}$ occurs in such a way that the three $\mathrm{Cl}$ atoms facing towards the monolayer tend to stabilize closer to the B atoms of the monolayer. This may be due to the possibility of interaction between the lone pairs of $\mathrm{Cl}$ and vacant $\mathrm{p}$ orbital of the $\mathrm{B}$ atoms. As a result, the $\mathrm{AlCl}_{4}$ molecule undergoes a slight deformation as the three $\mathrm{Al}-\mathrm{Cl}$ bonds facing towards the $\mathrm{BCN}$ monolayer get 
(a)

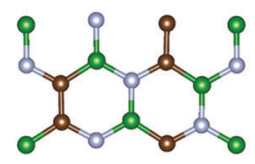

(b)

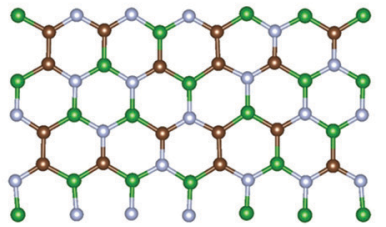

$\mathrm{RE}=0.29 \mathrm{eV}$ (c)

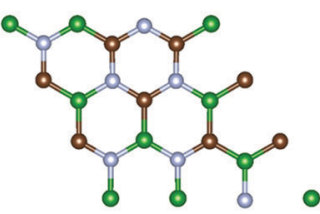

$\mathrm{RE}=0.68 \mathrm{eV}$

(d)

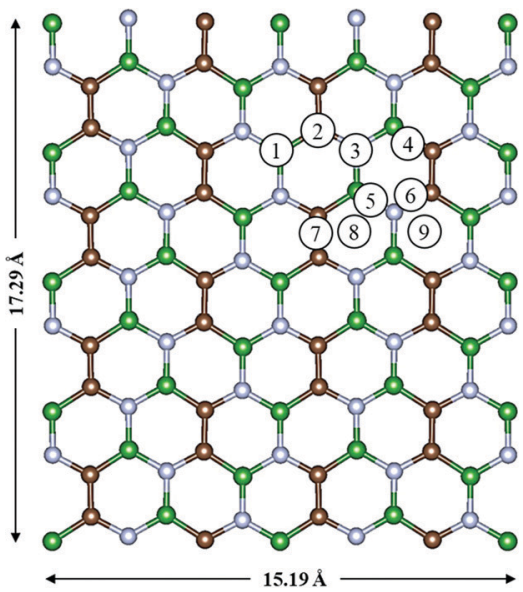

1- B Top

2- C Top

3- N Top

4- B-C Bridge

5- B-N Bridge

6- C-N Bridge

7- C-C Bridge

8- C-C-B-N-B-N Hollow

9- C-B-N-C-B-N Hollow

Fig. 1 Three plausible configurations (a)-(c) of the BCN monolayer with their relative energies, and (d) the top view of the possible adsorption sites on the $2 \times 4 \times 1$ supercell of BCN. Here, the green, brown, and blue colors represent the B, C and N atoms, respectively.

elongated to $2.17 \AA$ (from $2.15 \AA$ ), while the one facing upward gets shortened to $2.13 \AA$.

The adsorption of $\mathrm{Al}_{2} \mathrm{Cl}_{7}$ on the $\mathrm{BCN}$ monolayer was also investigated and the adsorption energy was calculated to be $-2.77 \mathrm{eV}$, which is much more favourable than the $\mathrm{AlCl}_{4}$ adsorption $(-2.36 \mathrm{eV})$. This is expected due to the presence of a higher number of electronegative $\mathrm{Cl}$ atoms in the $\mathrm{Al}_{2} \mathrm{Cl}_{7}$ anion, which can induce a higher charge transfer from the monolayer. However, despite being energetically favourable, there is less probability of $\mathrm{Al}_{2} \mathrm{Cl}_{7}$ adsorption during the charge/discharge cycle of the battery. Firstly, it is reported that for a 1:1 ratio of $[\mathrm{EMIm}] \mathrm{Cl}: \mathrm{AlCl}_{3}$, only $\mathrm{AlCl}_{4}$ exists and the ratio must be $1: 1.3$, indicating that the $\mathrm{AlCl}_{3}$ concentration should be higher to generate $\mathrm{Al}_{2} \mathrm{Cl}_{7}$ in the electrolyte. ${ }^{55}$ Thus, the concentration of the $\mathrm{Al}_{2} \mathrm{Cl}_{7}$ ions is much less compared to $\mathrm{AlCl}_{4}$. Second, during the charging of the battery by application of an external potential through the circuit, when $\mathrm{AlCl}_{4}$ intercalation takes place on the cathodic part, $\mathrm{Al}_{2} \mathrm{Cl}_{7}$ must undergo simultaneous reduction to generate $\mathrm{Al}$ and $\mathrm{AlCl}_{4}$.

$$
\begin{aligned}
& 4 \mathrm{Al}_{2} \mathrm{Cl}_{7}^{-}+3 \mathrm{e}^{-} \rightleftharpoons \mathrm{Al}+7 \mathrm{AlCl}_{4}{ }^{-} \text {(Anode) } \\
& \mathrm{C}_{n}+\mathrm{AlCl}_{4}^{-} \rightleftharpoons \mathrm{C}_{n}\left[\mathrm{AlCl}_{4}\right]+\mathrm{e}^{-} \text {(Cathode) }
\end{aligned}
$$

As a result, there is less chance that low concentrations of $\mathrm{Al}_{2} \mathrm{Cl}_{7}$ achieved by keeping the ratio greater than $1: 1$, can engage in binding with the cathode material. Based on the very low probability of $\mathrm{Al}_{2} \mathrm{Cl}_{7}$ being available for binding at the cathodic part, the voltage equation (eqn (5)) was derived, considering only $\mathrm{AlCl}_{4}$ intercalation.
Next, to identify the nature of interaction between the adsorbed $\mathrm{AlCl}_{4}$ and $\mathrm{BCN}$ monolayer, the charge density difference (CDD) was evaluated using eqn (8):

$$
\rho_{\mathrm{CDD}}=\rho^{\text {total }}-\sum_{i} \rho_{i}^{\text {fragments }}
$$

where $\rho^{\text {total }}$ is the total charge density of the $\mathrm{AlCl}_{4}$-absorbed BCN system, and $\rho_{i}^{\text {fragments }}$ is the charge density of the individual fragments from the system. The charge density of the individual fragments $\left(\rho_{i}^{\text {fragments }}\right)$ was calculated using the pseudo structure in which the individual fragment retained the same structure as that in the system, while the remaining fragments were deleted. The CDD plot of the $\mathrm{AlCl}_{4}$-absorbed $\mathrm{BCN}$ system at the most stable site is depicted in Fig. 2. The nature of interaction was found to be ionic. On adsorption, there is an accumulation of (a)

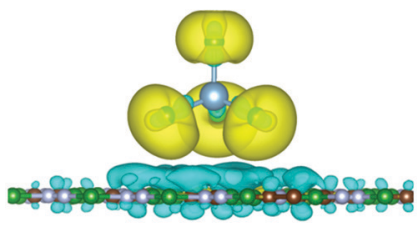

(b)

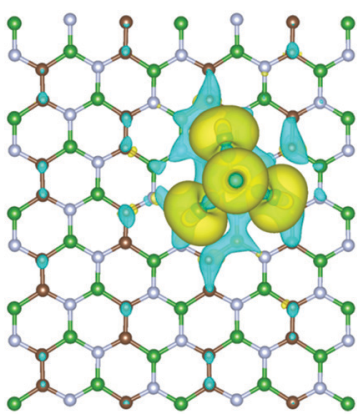

Fig. 2 (a) Side and (b) top view of the charge density difference plot for $\mathrm{AlCl}_{4}$ adsorbed on the $\mathrm{BCN}$ monolayer. Here, the green, brown, and blue colors represent the $\mathrm{B}, \mathrm{C}$ and $\mathrm{N}$ atoms, respectively. Here, isosurface $=0.0009|e| \AA^{-3}$ (yellow for $\Delta \rho>0$ and blue for $\Delta \rho<0$ ). 
electronic charge on each chlorine atom of $\mathrm{AlCl}_{4}$, while depletion of electronic charge can be detected on the BCN monolayer atoms close to the adsorbed $\mathrm{AlCl}_{4}$. As a result, the oxidation of the BCN monolayer cathode (along with simultaneous reduction of $\mathrm{AlCl}_{4}$ ) during the charging mechanism can be concluded. Moreover, the charge depletion can be seen to occur from the $\mathrm{C}$ and $\mathrm{N}$ atoms, and not $\mathrm{B}$ atoms among the atoms surrounding the adsorption site due to the difference in electron density among them. Bader charge analysis of the system also shows that $\mathrm{AlCl}_{4}$ accepts a net electronic charge of $0.9|e|$ from the BCN monolayer upon adsorption, signifying the cathode oxidation during charging.

\subsection{Electrochemical and electronic properties}

To calculate the electrochemical properties (like voltage and specific storage capacity) for the BCN cathode material, the BCN monolayer was systematically subjected to adsorb different concentrations of $\mathrm{AlCl}_{4}$. For the different concentrations of adsorbed $\mathrm{AlCl}_{4}$, all possible configurations were considered to find out the most stable configurations, as represented in Fig. 3 and Fig. S3 (ESI $\dagger$ ). The maximum number of $\mathrm{AlCl}_{4}$ adsorbed on a $2 \times 4 \times 1$ BCN monolayer was found to be 14 .

To investigate the variation in adsorption behavior of the BCN monolayer with increasing concentration of $\mathrm{AlCl}_{4}$ adsorption, we calculated the adsorption energy for all cases, as presented in Table 1 . As the concentration of $\mathrm{AlCl}_{4}$ adsorbed on $\mathrm{BCN}$ increases, the adsorption energy per $\mathrm{AlCl}_{4}$ molecule (as well as the charge transferred per $\mathrm{AlCl}_{4}$ molecule) was found to decrease. This decrease in adsorption energy might be due to the increase in repulsive forces, as the number of adsorbed $\mathrm{AlCl}_{4}$ molecule increases on the monolayer. The $\mathrm{AlCl}_{4}$ molecules occupy the most stable hollow site surrounded by the
Table 1 The calculated adsorption energies, charge transfer to per $\mathrm{AlCl}_{4}$ from $\mathrm{BCN}$ and calculated theoretical voltage for different concentrations of $\mathrm{AlCl}_{4}$ adsorbed on the $\mathrm{BCN}$ monolayer

\begin{tabular}{llll}
\hline $\begin{array}{l}\text { Number of } \mathrm{AlCl}_{4} \\
\text { adsorbed }\end{array}$ & $\begin{array}{l}\text { Adsorption } \\
\text { energy/AlCl }\end{array}$ (eV) & $\begin{array}{l}\text { Charge transfer } \\
\text { to per AlCl } \\
\text { molecule }(|e|)\end{array}$ & Voltage (V) \\
\hline 1 & -2.36 & -0.90 & 0.84 \\
2 & -2.21 & -0.88 & 0.99 \\
3 & -2.05 & -0.82 & 1.15 \\
4 & -1.95 & -0.75 & 1.24 \\
5 & -1.85 & -0.70 & 1.35 \\
6 & -1.79 & -0.67 & 1.41 \\
7 & -1.74 & -0.64 & 1.46 \\
8 & -1.70 & -0.61 & 1.50 \\
9 & -1.63 & -0.58 & 1.56 \\
10 & -1.59 & -0.56 & 1.60 \\
11 & -1.55 & -0.54 & 1.65 \\
12 & -1.52 & -0.52 & 1.67 \\
13 & -1.46 & -0.51 & 1.74 \\
14 & -1.38 & -0.47 & 1.81 \\
& & &
\end{tabular}

C-C-B-N-B-N ring in the monolayer up to $12 \mathrm{AlCl}_{4}$ molecules. On further increasing the concentration, $\mathrm{AlCl}_{4}$ molecules do not necessarily occupy the most stable site and instead try to maintain distance among themselves, as shown in Fig. 3d. The maximum of $14 \mathrm{AlCl}_{4}$ molecules are adsorbed reversibly on a $2 \times 4 \times 1$ supercell of the BCN monolayer. Further adsorption of $\mathrm{AlCl}_{4}$ results in dissociation into $\mathrm{AlCl}_{3}$ and $\mathrm{Cl}$, as shown in Fig. S4 (ESI $\dagger$ ), which is not recommended for the reversible charging/discharging mechanism of a cathode material. However, the BCN monolayer was not found to show any kind of structural distortion on the adsorption of $14 \mathrm{AlCl}_{4}$ molecules, and remained stable to be used as cathode material.

We calculated the theoretical charging voltage using eqn (5) for the systematic adsorption of $\mathrm{AlCl}_{4}$ molecules on the BCN (a)
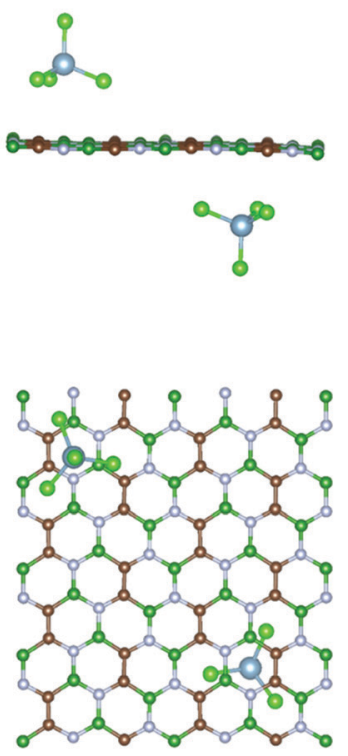

(b)
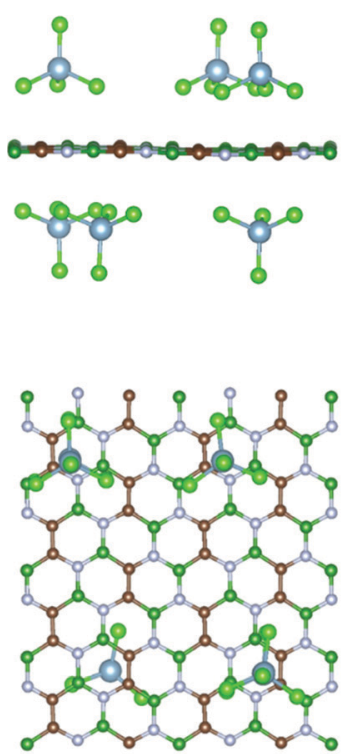

(c)
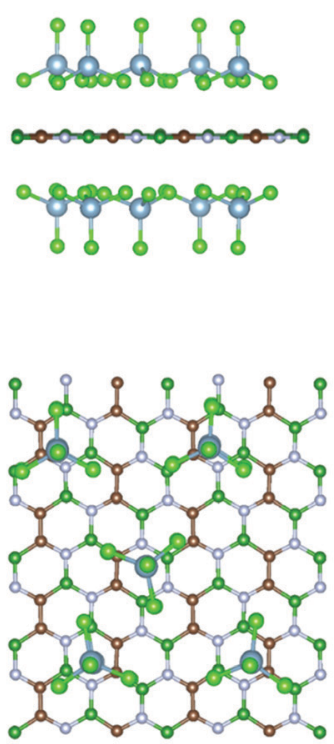

(d)
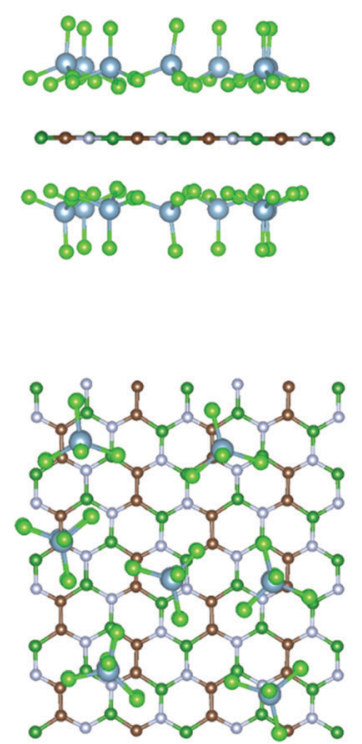

Fig. 3 Side and top views of the most stable configurations of the $\mathrm{AlCl}_{4}$-adsorbed $\mathrm{BCN}$ monolayer at different $\mathrm{AlCl}_{4} \mathrm{Concentrations}$ : (a) $\left(\mathrm{AlCl}_{4}\right)_{2} \mathrm{BCN}$, (b) $\left(\mathrm{AlCl}_{4}\right)_{6} \mathrm{BCN}$, (c) $\left(\mathrm{AlCl}_{4}\right)_{10} \mathrm{BCN}$, and (d) $\left(\mathrm{AlCl}_{4}\right)_{14} \mathrm{BCN}$. 
(a)

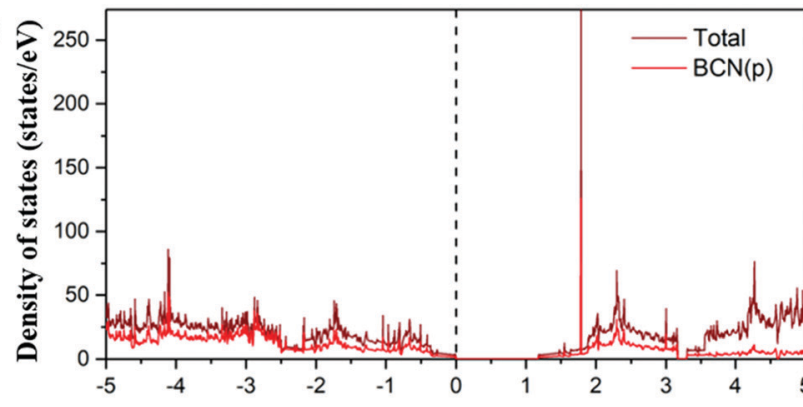

(b)

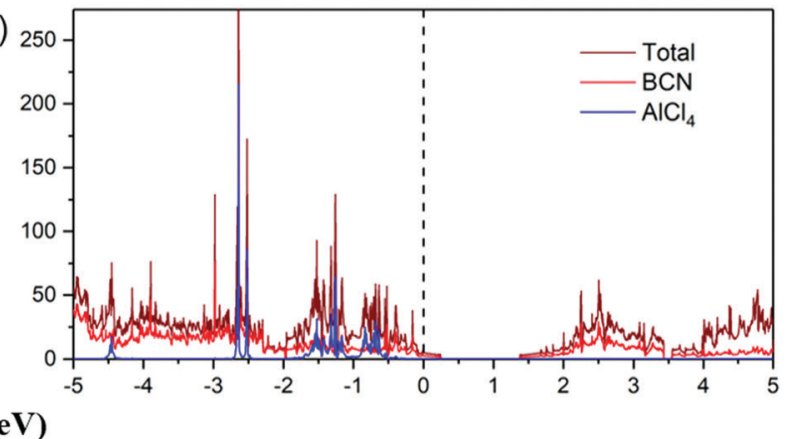

Fig. 4 Total and partial density of states of the (a) $\mathrm{BCN}$ monolayer and (b) $\mathrm{AlCl}_{4}$-adsorbed $\mathrm{BCN}$ monolayer. The Fermi level is set at zero.

monolayer. From Table 1, it is evident that the voltage for the adsorption of the first $\mathrm{AlCl}_{4}$ molecule is only $0.84 \mathrm{~V}$, which continues to increase with increasing concentration of $\mathrm{AlCl}_{4}$. Hence, the average voltage obtained is $1.43 \mathrm{~V}$. This seems to be inversely proportional with the change in adsorption energy per $\mathrm{AlCl}_{4}$, which is understandable from eqn (5). A more stable $\mathrm{AlCl}_{4}$-adsorbed system will require a lower charging voltage. As the $\mathrm{AlCl}_{4}$ concentration increases, the system gets destabilized due to the repulsion among the adsorbed anions, thus requiring a high charging voltage. ${ }^{24}$ The open circuit voltage for the maximum $\mathrm{AlCl}_{4}$-adsorbed system is $1.8 \mathrm{~V}$, which is comparatively lower than that experimentally reported for the graphite cathode $(2 \mathrm{~V}){ }^{16}$ However, the theoretical specific capacity calculated by eqn (6) for the BCN monolayer at the maximum $\mathrm{AlCl}_{4}$ adsorption is $316.9 \mathrm{~mA} \mathrm{~h} \mathrm{~g}_{\mathrm{BCN}}{ }^{-1}$, which is much more than that experimentally reported for the graphite cathode $\left(70 \mathrm{~mA} \mathrm{~h} \mathrm{~g}{ }^{-1}\right) .{ }^{16}$ Hence, the BCN monolayer can be considered an attractive high specific capacity cathode material that is suitable for $\mathrm{Al}$ dual-ion batteries.

Furthermore, the electronic conductivity of a material also plays a crucial role in determining its suitability as a cathode material. We have plotted the total and partial density of states (DOS) of the pristine $\mathrm{BCN}$ and $\mathrm{AlCl}_{4}$-adsorbed $\mathrm{BCN}$ system, as represented in
Fig. 4. In previous reports, configurations (b) and (a) of BCN have been found to be semiconducting in nature with a band gap of $1.5 \mathrm{eV}$ and $1.18 \mathrm{eV}$ using the HSE06 density functional and PBE functional, respectively. ${ }^{34,56}$ The DOS plots of pristine BCN of configuration (a) show the material to be semiconducting in nature with a small bandgap of $1.18 \mathrm{eV}$. The states near the Fermi level are mainly occupied by the BCN (2p) states. However, the DOS picture completely changes on adsorption of $\mathrm{AlCl}_{4}$ on the most stable site of the BCN monolayer. The Fermi level can be detected to shift towards the valence band compared to the pristine BCN DOS plot due to the charge transfer from $\mathrm{BCN}$ to $\mathrm{AlCl}_{4}$, which destabilizes the valence band. As a result, the states are introduced at the Fermi level, as there is interaction between the p states of $\mathrm{AlCl}_{4}$ and $\mathrm{BCN}$. The band gap width was also observed to shrink with increasing concentration of $\mathrm{AlCl}_{4}$ adsorption $(1.09 \mathrm{eV}, 1.04 \mathrm{eV}$ and $1.02 \mathrm{eV}$ for 7, 10 and $14 \mathrm{AlCl}_{4}$ adsorption, respectively), as represented in Fig. S5 (ESI $\dagger$ ). Hence, the conductivity of the BCN monolayer may increase with $\mathrm{AlCl}_{4}$ adsorption, and satisfies the criteria for electronic conductivity of the cathode material.

\subsection{Diffusion properties}

Another crucial factor that determines the performance of a battery is the charge/discharge rate of its cathode material.
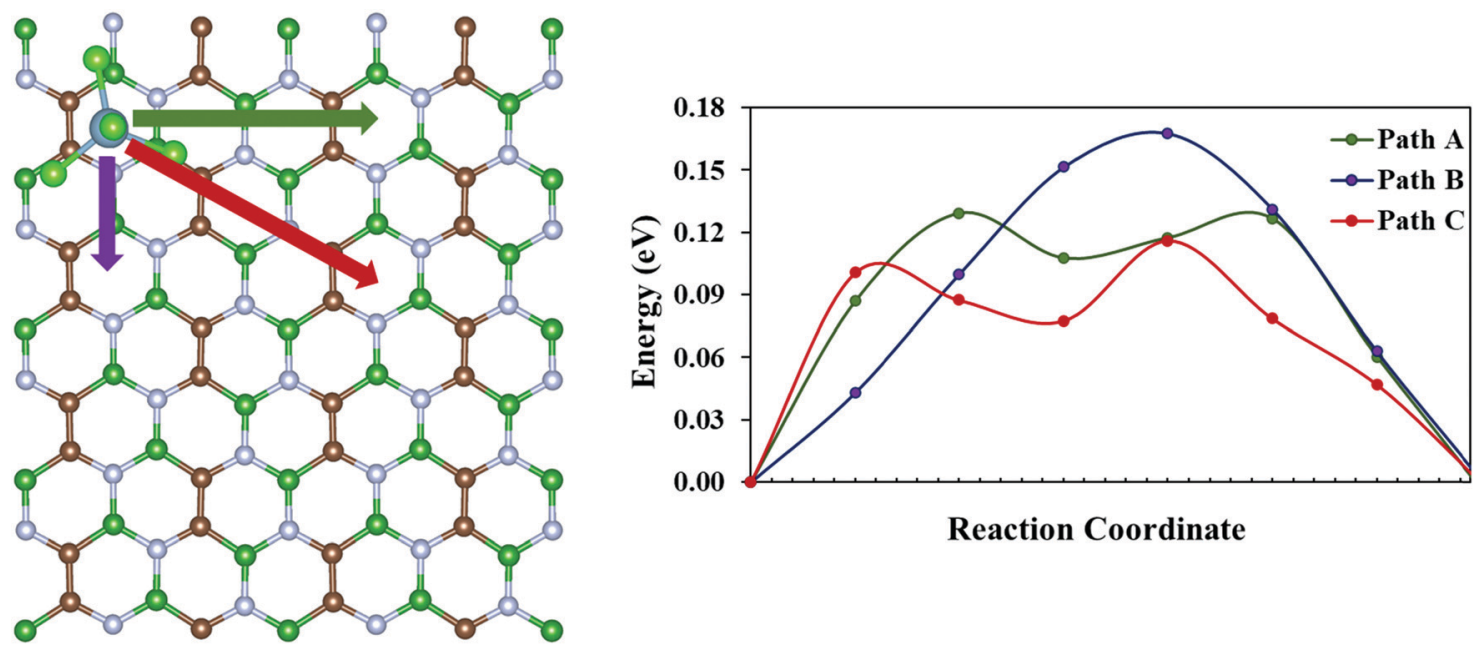

Reaction Coordinate

Fig. 5 Possible pathways for $\mathrm{AlCl}_{4}$ diffusion on the $\mathrm{BCN}$ monolayer and their corresponding diffusion energies. 
Table 2 Diffusion energy barrier and average distance of $\mathrm{Cl}$ atoms of $\mathrm{AlCl}_{4}$ from the nearest $\mathrm{B}$ atoms in the $\mathrm{BCN}$ monolayer

\begin{tabular}{lll}
\hline Diffusion path & $\begin{array}{l}\text { Diffusion energy } \\
\text { barrier }(\mathrm{eV})\end{array}$ & $\begin{array}{l}\text { Average distance of } \\
\mathrm{Cl} \text { atoms of } \mathrm{AlCl}_{4} \text { from the } \\
\text { nearest B atoms in } \mathrm{BCN}(\AA)\end{array}$ \\
\hline Path A & 0.13 & 3.50 \\
Path B & 0.17 & 3.68 \\
Path C & 0.12 & 3.47 \\
\hline
\end{tabular}

The charge/discharge rate depends on the migration of the adsorbed species within the cathode system. Thus, we have calculated the diffusion barrier for $\mathrm{AlCl}_{4}$ within similar adsorption sites of the BCN monolayer using the CI-NEB method. For this, a $2 \times 4 \times 1$ supercell of the BCN monolayer has been considered. Site 8 , which corresponds to the hollow site surrounded by C-C-B-N-B-N ring (as discussed earlier in Subsection 3.2), is taken as both the starting and the end point for $\mathrm{AlCl}_{4}$ diffusion because of its least adsorption energy. There are three possible pathways (path A, path B and path C) for $\mathrm{AlCl}_{4}$ diffusion, as illustrated in Fig. 5. The energy vs. reaction coordinate graph shows the anisotropic diffusion behavior, as path $\mathrm{C}$ is the most favorable path for $\mathrm{AlCl}_{4}$ diffusion with a smaller diffusion barrier $(0.12 \mathrm{eV})$ compared to that of path $\mathrm{A}$ and path $\mathrm{B}$, as represented in Table 2 . Hence, we try to examine the stability of the highest energy transition state for path C compared to that of path A and path B. This relative stability of the highest energy transition states can be explained based on their orientations, as represented in Fig. S6 (ESI $\dagger$ ). While trying to find the most stable orientations of $\mathrm{AlCl}_{4}$ adsorption, we saw the tendency of the three $\mathrm{Cl}$ atoms of the $\mathrm{AlCl}_{4}$ molecule in remaining closer to the $\mathrm{B}$ atoms of the $\mathrm{BCN}$ monolayer. Along the same line of thought, we find that the $\mathrm{Cl}$ atoms of $\mathrm{AlCl}_{4}$ for the most stable highest energy transition state (corresponding to path $\mathrm{C}$ ) maintain a shorter average distance $(3.47 \AA)$ to their nearest $\mathrm{B}$ atoms of the monolayer compared to the corresponding transition states of path $\mathrm{A}$ and $\mathrm{B}$, as given in Table 2. Overall, we find that the diffusion barrier of the minimum energy pathway $(0.12 \mathrm{eV})$ is lower than the diffusion barrier calculated for the graphene bilayer as the cathode $(0.19 \mathrm{eV})$ in a previous report. ${ }^{54}$ This demonstrates the ability of the $\mathrm{BCN}$ monolayer to allow trouble-free $\mathrm{AlCl}_{4}$ diffusion.

\section{Conclusion}

In this work for the first time, the applicability of the BCN monolayer as a potential $\mathrm{AlCl}_{4}$ intercalating cathode material for Al dual-ion batteries has been discussed. The results show that $\mathrm{AlCl}_{4}$ adsorbs tetrahedrally with the $\mathrm{BCN}$ monolayer with reasonable adsorption energy. Furthermore, the Bader charge analysis and CDD show significant charge transfer of $0.9|e|$ from the $\mathrm{BCN}$ monolayer to $\mathrm{AlCl}_{4}$, demonstrating the oxidation of $\mathrm{BCN}$ and reduction of $\mathrm{AlCl}_{4}$ during the charging mechanism. The systematic step-by-step adsorption of $\mathrm{AlCl}_{4}$ yields a maximum adsorption of $14 \mathrm{AlCl}_{4}$ molecules on our considered BCN monolayer. As the number of adsorbed molecules increase, the adsorption energy per molecule decreases due to the repulsion among the anions. Also, the BCN monolayer retains its structure during the adsorption process, implying reversibility of the $\mathrm{AlCl}_{4}$ adsorption process. The voltage and capacity calculations reveal a significant open circuit voltage of $1.8 \mathrm{~V}$ (average voltage

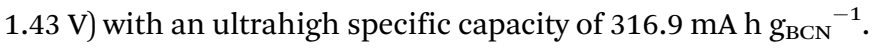
The DOS calculations predict the increase in conductivity of the $\mathrm{BCN}$ cathode on $\mathrm{AlCl}_{4}$ adsorption. Anisotropic properties are detected during the diffusion energy barrier calculations along different paths. The small energy barrier of $0.12 \mathrm{eV}$ obtained for $\mathrm{AlCl}_{4}$ diffusion across the monolayer also predicts an unrestricted diffusion of the $\mathrm{AlCl}_{4}$ molecule. Overall, our study shows that the favorable $\mathrm{AlCl}_{4}$ adsorption, substantial voltage, ultrahigh capacity, fast charge/discharge rate and the electrical conductivity of the BCN monolayer presents it as an alternative cathode material for Al dual-ion batteries.

\section{Conflicts of interest}

There are no conflicts of interest to declare.

\section{Acknowledgements}

We thank IIT Indore for lab and computing facilities. This work is supported by DST-SERB (Project Number CRG/2018/001131), and SPARC (Project Number SPARC/2018-2019/P116/SL) New Delhi. H. S. thanks IIT Indore for providing research facilities. S. D. thanks CSIR for a research fellowship.

\section{References}

1 M. Armand and J.-M. Tarascon, Nature, 2008, 451, 652-657.

2 Y. Tang, Y. Zhang, W. Li, B. Ma and X. Chen, Chem. Soc. Rev., 2015, 44, 5926-5940.

3 J. Lee, A. Urban, X. Li, D. Su, G. Hautier and G. Ceder, Science, 2014, 343, 519-522.

4 J. B. Goodenough and Y. Kim, Chem. Mater., 2010, 223, 587-603.

5 S. K. Martha, B. Hariprakash, S. A. Gaffoor, D. C. Trivedi and A. K. Shukla, J. Chem. Sci., 2006, 118, 93-98.

6 G. J. May, A. Davidson and B. Monahov, J. Energy Storage, 2018, 15, 145-157.

7 R. H. Newman, J. Power Sources, 1994, 52, 149-153.

8 S. Rasul, S. Suzuki, S. Yamaguchi and M. Miyayama, Electrochim. Acta, 2012, 82, 243-249.

9 R. Zhang and C. Ling, MRS Energy Sustainability, 2016, 3, E1. 10 C. Xu, B. Li, H. Du and F. Kang, Angew. Chem., Int. Ed., 2012, 51, 933-935.

11 B. Lee, H. R. Lee, H. Kim, K. Y. Chung, B. W. Cho and S. H. Oh, Chem. Commun., 2015, 51, 9265-9268.

12 Y. Ru, S. Zheng, H. Xue and H. Pang, J. Mater. Chem. A, 2019, 7, 14391-14418.

13 N. S. Hudak, J. Phys. Chem. C, 2014, 118, 5203-5215.

14 Q. Li and N. J. Bjerrum, J. Power Sources, 2002, 110, 1-10. 
15 N. Jayaprakash, S. K. Das and L. A. Archer, Chem. Commun., 2011, 47, 12610-12612.

16 M.-C. Lin, M. Gong, B. Lu, Y. Wu, D.-Y. Wang, M. Guan, M. Angell, C. Chen, J. Yang, B.-J. Hwang and H. Dai, Nature, 2015, 520, 324-328.

17 P. Bhauriyal, A. Mahata and B. Pathak, Phys. Chem. Chem. Phys., 2017, 19, 7980-7989.

18 D. Y. Wang, C. Y. Wei, M. C. Lin, C. J. Pan, H. L. Chou, H. A. Chen, M. Gong, Y. Wu, C. Yuan, M. Angell and Y. J. Hsieh, et al., Nat. Commun., 2017, 8, 14283.

19 Y. Wu, M. Gong, M.-C. Lin, C. Yuan, M. Angell, L. Huang, D.-Y. Wang, X. Zhang, J. Yang, B.-J. Hwang and H. Dai, Adv. Mater., 2016, 28, 9218-9222.

20 H. Sun, W. Wang, Z. Yu, Y. Yuan, S. Wang and S. Jiao, Chem. Commun., 2015, 51, 11892-11895.

21 H. Sun, Z. Xu and C. Gao, Adv. Mater., 2013, 25, 2554-2560.

22 X. Huang, Y. Liu, H. Zhang, J. Zhang, O. Noonana and C. Yu, J. Mater. Chem. A, 2017, 5, 19416-19421.

23 P. Bhauriyal, A. Mahata and B. Pathak, J. Phys. Chem. C, 2017, 121, 9748-9756.

24 P. Bhauriyal, P. Garg, M. Patel and B. Pathak, J. Mater. Chem. A, 2018, 6, 10776-10786.

25 P. Bhauriyal, G. Bhattacharyya, K. S. Rawat and B. Pathak, J. Phys. Chem. C, 2019, 123, 3959-3967.

26 L. Zhang, C. Chen, H. Luo, X. Zhou and Z. Liu, Adv. Energy Mater., 2017, 7, 1700034.

27 H. Chen, F. Guo, Y. Liu, T. Huang, B. Zheng, N. Ananth, Z. Xu, W. Gao and C. Gao, Adv. Mater., 2017, 29, 1605958.

28 J. Tu, H. Lei, Z. Yu and S. Jiao, Chem. Commun., 2018, 54, 1343-1346.

29 C. Liu, Z. Yu, D. Neff, A. Zhamu and B. Z. Jang, Nano Lett., 2010, 10, 4863-4868.

30 C. Tan, X. Cao, X.-J. Wu, Q. He, J. Yang, X. Zhang, J. Chen, W. Zhao, S. Han, G.-H. Nam, M. Sindoro and H. Zhang, Chem. Rev., 2017, 117, 6225-6331.

31 Q. Sun, Y. Dai, Y. Ma, T. Jing, W. Wei and B. Huang, J. Phys. Chem. Lett., 2016, 7, 937-943.

32 H. R. Jiang, Z. Lu, M. C. Wu, F. Ciucci and T. S. Zhao, Borophene: Nano Energy, 2016, 23, 97-104.

33 P. Bhauriyal, A. Mahata and B. Pathak, J. Phys. Chem. C, 2018, 122, 2481-2489.
34 S. Beniwal, J. Hooper, D. P. Miller, G. Costa, P. S. Chen, S. Y. Liu, P. A. Dowben, E. C. H. Sykes, E. Zurek and A. Enders, ACS Nano, 2017, 11, 2486-2493.

35 S. Lizzit and A. Baraldi, Catal. Today, 2010, 154, 68-74.

36 F. Orlando, R. Larciprete, P. Lacovig, I. Boscarato, A. Baraldi and S. Lizzit, J. Phys. Chem. C, 2012, 116, 157.

37 M. Corso, W. Auwärter, M. Muntwiler, A. Tamai, T. Greber and J. Osterwalder, Science, 2004, 303, 217.

38 S. Thomas and S. U. Lee, RSC Adv., 2019, 9, 1238-1246.

39 P. E. Blöchl, Phys. Rev. B: Condens. Matter Mater. Phys., 1994, 50, 17953.

40 G. Kresse and J. Furthmüller, Comput. Mater. Sci., 1996, 6, 15-50.

41 G. Kresse and J. Furthmüller, J. Phys. Rev. B: Condens. Matter Mater. Phys., 1996, 54, 11169-11186.

42 G. Kresse and J. Hafner, Phys. Rev. B: Condens. Matter Mater. Phys., 1994, 49, 14251.

43 J. P. Perdew, K. Burke and M. Ernzerhof, Phys. Rev. Lett., 1997, 78, 1396.

44 S. Grimme, J. Antony, S. Ehrlich and H. Krieg, J. Chem. Phys., 2010, 132, 154104.

45 G. Henkelman, B. P. Uberuaga and H. Jónsson, J. Chem. Phys., 2000, 113, 9901-9904.

46 R. F. W. Bader, Chem. Rev., 1991, 91, 893-928.

47 G. Henkelman, A. Arnaldsson and H. Jónsson, Comput. Mater. Sci., 2006, 36, 354-360.

48 E. Sanville, S. D. Kenny, R. Smith and G. J. Henkelman, J. Comput. Chem., 2007, 28, 899-908.

49 W. Tang, E. Sanville and G. Henkelman, J. Phys.: Condens. Matter, 2009, 21, 084204.

50 S. Nosé, J. Chem. Phys., 1984, 81, 511-519.

51 M. K. Aydinol, A. F. Kohan, G. Ceder, K. Cho and J. Joannopoulos, Phys. Rev. B: Condens. Matter Mater. Phys., 1997, 56, 1354.

52 M. L. Agiorgousis, Y.-Y. Sun and S. Zhang, ACS Energy Lett., 2017, 2, 689-693.

53 V. O. Özçelik and S. Ciraci, J. Phys. Chem. C, 2013, 117, 2175-2182.

54 S. C. Jung, Y. J. Kang, D. J. Yoo, J. W. Choi and Y. K. Han, J. Phys. Chem. C, 2016, 120, 13384-13389.

55 T. Jiang, M. J. Chollier Brym, G. Dubé, A. Lasia and G. M. Brisard, Surf. Coat. Technol., 2006, 201, 1-9.

56 S. Thomas, M. S. Manju, K. M. Ajith, S. U. Lee and M. Asle Zaeem, Phys. E, 2020, 123, 114180. 